\title{
Changes in severity of traffic related trauma aged $18+$ admitted to a local level 2 trauma centre after the introduction of the Mobile Emergency Care Unit at Southern Funen. A pilot study
}

Stine Hebsgaard ${ }^{1 *}$, Stine T Zwisler ${ }^{1}$, Jens Lauritsen ${ }^{2}$

From 6th Danish Emergency Medicine Conference

Odense, Denmark. 20-21 November 2014

\section{Background}

Centralizing and specializing in Danish health care is ongoing. Around the country Mobile Emergency Care Units (MECU) are introduced during the past years. Pre-hospital triage is important to evaluate at which trauma level the severely injured patients must be received. The aim of our study was to evaluate changes in the severity in $18+$ traffic related trauma admitted to a level 2 centre at Odense University Hospital, Svendborg Hospital (OUH, SH) after the introduction of a local MECU.

\section{Methods}

The study was a retrospective study covering a ten-year period from 2002-2012. All admissions from traffic accidents to $\mathrm{OUH}, \mathrm{SH}$ were extracted from the hospital inpatient registry for patients aged $18+$. Based on clinical record reviews and radiology findings, we decided if the patient was multi trauma (MT) defined as received by trauma response team and/or CT trauma scanned. We evaluated the diagnoses and assigned whether maximum Abbreviated Injury Score (mAIS) was three or more (severe injury). A total of 363 traffic injury patients were identified. Five were undeterminable in MT status and 137 non-MT patients were excluded, giving 221 adult MT cases for analysis. From the years 2002-2006 (118 MT) before and 2010-2012 (46 MT) - after implementing the MECU 24/7 in Svendborg September $1^{\text {st }}$ 2009. The years 2007-2009 were extracted since the MECU was launched part time in 2007. The study was performed as a pilot study including patients born on the 1st to 6th of each month.

\section{Results}

Proportion of $\mathrm{mAIS} \geq 3$ in the years before implementing the MECU in Svendborg was $17.1 \%$ (CI: 10.2-24.0) versus $23.9 \%$ (CI: 11.1-36.7) in the years after the implementation $(\mathrm{p}=0.32)$.

\section{Conclusions}

There was no significant change in the proportion of severely injured patients admitted to this level 2 trauma centre after implementation of the local MECU in this study.

\section{Authors' details}

${ }^{1}$ Department of Anaesthesiology \& Intensive Care, OUH Odense University Hospital, Svendborg, Denmark. ${ }^{2}$ Accident Analysis Group, Department of Orthopaedics, OUH Odense University Hospital, Odense, Denmark.

Published: 16 July 2015

doi:10.1186/1757-7241-23-S1-A5

Cite this article as: Hebsgaard et al: Changes in severity of traffic related trauma aged $18+$ admitted to a local level 2 trauma centre after the introduction of the Mobile Emergency Care Unit at Southern Funen. A pilot study. Scandinavian Journal of Trauma, Resuscitation and Emergency Medicine 2015 23(Suppl 1):A5.

\footnotetext{
* Correspondence: Stine.hebsgaard@gmail.com

'Department of Anaesthesiology \& Intensive Care, OUH Odense University

Hospital, Svendborg, Denmark

Full list of author information is available at the end of the article
} 